\title{
Full life cycle analysis of Dunhill International cigarettes as produced by British American Tobacco
}

\section{ROBERT SARICH}

\section{Abstract}

This article aims to explore the life cycle of cigarettes and its impacts, using the full life cycle analysis theoretical framework as the underlying basis of the study. Dunhill International cigarettes are referenced throughout as a specific cigarette brand for investigation and analysis due to their popularity and global appeal, although much of the article discusses and refers to cigarettes more broadly due to the relatively homogeneous nature of the product. The product, company and industry overview introduces the topic, which then leads into a thorough discussion detailing each phase of the product life cycle. This sets the stage for an in-depth analysis of the economic, environmental, and social impacts, both positive and negative, of Dunhill cigarettes and tobacco more broadly with reference to the broken window fallacy. The article closes with a brief conclusion and recommendations for further research.

\section{Product history and details}

Dunhill International cigarettes first entered the market in 1967, the same year that Rothmans International gained a controlling stake in the Dunhill cigarette company (Wilberg \& Vermeulen, 2008). Dunhill International cigarettes grew in popularity over the decades and are now exported globally including throughout Europe, North and South America, Asia and Australia (Mayer, 2010).

Dunhill International cigarettes are much like other cigarettes in that they share the same three central elements. These are the paper, the tobacco itself, and the filter at the end of the cigarette. Dunhill cigarettes are available in a range of different packaging, from hardened paper packets to aluminium tins and cardboard cartons (Mayer, 2010). For the purpose of this article, this article will focus primarily on the three aforementioned central components of Dunhill International cigarettes since the packaging varies greatly and is not the primary focus. 


\section{Company history}

In 1999, Rothmans International merged with British American Tobacco while continuing to operate under the name of the latter (Wilberg \& Vermeulen, 2008). British American Tobacco products are sold in more than 180 countries globally and hold the market-leading position in more than 50 countries. The Dunhill brand of cigarettes remains one of the four leading brands operated by British American Tobacco, along with Pall Mall, Lucky Strike, and Kent (British American Tobacco, 2016d). As at December 31 2015, the group had total revenue of $£ 13,104$ million, with profit from operations totalling $£ 4,992$ million. It is the second largest producer of tobacco by global market share (British American Tobacco, 2016b).

\section{The global tobacco industry}

The global cigarette industry sells roughly 5,600 billion cigarettes per year. One billion of the world's smokers live in developing countries. Cigarette smoking continues to rise in developing countries, but continues to fall in developed countries. This trend is largely attributed to the fact that developed countries have a higher tendency to employ anti-smoking measures such as smoke-free zones, taxation on tobacco products, greater restrictions on sale and limits on how cigarettes can be marketed. Every year, 5,600 billion cigarettes are smoked, and it is estimated that 1 billion people will die of smoking-related causes in the twenty-first century if current trends continue (Proctor, 2011).

\section{Theoretical framework: Full life cycle analysis}

In order to analyse sustainability issues regarding the use of Dunhill cigarettes, it is important to introduce theory relating to the full life cycle analysis of a product. The theory allows for each and every stage of the life of the product to be analysed and critiqued. The five stages in life cycle analysis have been tabulated in Figure 1.

\begin{tabular}{|l|l|}
\hline $\begin{array}{l}\text { Stage 1: Raw } \\
\text { Material Acquisition }\end{array}$ & $\begin{array}{l}\text { This stage includes material harvesting and transportation to } \\
\text { manufacturing sites. }\end{array}$ \\
\hline Stage 2: Processing & $\begin{array}{l}\text { This stage involves materials processing and transportation of the } \\
\text { processed materials to production sites. }\end{array}$ \\
\hline $\begin{array}{l}\text { Stage 3: } \\
\text { Manufacturing }\end{array}$ & $\begin{array}{l}\text { This stage includes product manufacture and assembly, } \\
\text { packaging, and transportation to the location of final distribution. }\end{array}$ \\
\hline Stage 4: Product Life & $\begin{array}{l}\text { This stage includes energy and emissions during normal product } \\
\text { life, required maintenance, and product reuse (such as } \\
\text { refurbishing, material reuse). }\end{array}$ \\
\hline $\begin{array}{l}\text { Stage 5: Waste } \\
\text { Management/End } \\
\text { of Life }\end{array}$ & $\begin{array}{l}\text { This stage relates to what happens to the product after its use, } \\
\text { and includes elements such as recycling, landfills, liquid waste, } \\
\text { and gas emissions. }\end{array}$ \\
\hline
\end{tabular}

Figure 1: A tabulated overview of the five stages of life cycle analysis. 


\section{Applying each stage of life cycle analysis to Dunhill International}

\section{Raw material acquisition}

The tobacco used in Dunhill International cigarettes is primarily Virginia tobacco. This type of tobacco is named after the state of the USA where it was first grown, but is sourced by British American Tobacco from a variety of locations including Florida, Brazil and Zimbabwe (British American Tobacco, 2016a). Details do not publicly exist regarding the specific blend of tobaccos used in Dunhill International cigarettes, although it is known British American Tobacco also sources tobacco from other locations such as Central America, Malawi, Uganda and Mozambique (British American Tobacco, 2016a). Deforestation and land clearing to make way for tobacco crops is a serious environmental impact, which will be discussed further later in the article (Makoye, 2012).

Tobacco production uses over 5.3 million hectares of arable land globally (Stanton, 2005). To put this number in perspective, it is worth considering the fact that the total landmass of Taiwan is only 3.6 million hectares (Ken-cheng, 2008). Some machinery exists for the mechanical harvesting of tobacco leaves, but its use is relatively uncommon since the vast majority of tobacco is harvested by hand (British American Tobacco, 2016a).

The cigarette papers and filters also require raw materials to be acquired. Cigarette paper is made using seed flax. This has been commonly cultivated throughout the United States and Canada since the 1930s for the sole purpose of creating cigarette papers (Vernier, 1998). The cigarette filters of Dunhill International are made using cellulose acetate (British American Tobacco, 2016c). This acetate is derived from wood pulp, which is sourced from a variety of trees grown worldwide including pine, eucalyptus and birch trees (Vernier, 1998).

\section{Processing}

Tobacco leaf curing and processing usually occurs at the same farm in which the crop is grown (British American Tobacco, 2016c). There are three main ways of curing the type of tobacco used in Dunhill International cigarettes. These are aircuring, in which it is simply hung to dry; flue-curing, using heat to dry the leaf; and sun-curing, by laying the leaves outside to dry with direct sunlight (British American Tobacco, 2016a).

The tobacco leaves are further processed typically at the location they were grown after the curing process is complete. All stems are removed from the tobacco leaves. This is followed by the leaves then being mechanically crushed, ground, and cut to 
the ideal size for cigarettes (British American Tobacco, 2016c). Processed tobacco, papers, and filters are then transported to the nearest factory typically via freight train, trucks and ships, depending on location (Vernier, 1998).

\section{Manufacturing}

Due to the sheer volumes involved with supplying Dunhill cigarettes to the global community, British American Tobacco has more than 44 factories in 41 countries where its cigarettes are manufactured (British American Tobacco, 2016b). After tobacco, papers and filters arrive, they undergo necessary checks to ensure that they meet expected standards. After being checked, the tobacco for the Dunhill International cigarettes is carefully blended (British American Tobacco, 2016c).

The actual manufacturing process is highly automated, with machines specifically designed for cigarette rolling being continuously provided with the papers and filters. The machines are also entirely capable of quality control as well, with very little human intervention required (British American Tobacco, 2016c). Production quantity varies by location, but the majority of machines are capable of producing tens of thousands of cigarettes per hour (Proctor, 2011). Packing machines at the same factories pack all cigarettes produced into tins and packets, which are then put in to storage to later be transported to larger retail companies who will then distribute Dunhill International cigarettes to their network to be purchased by consumers (Vernier, 1998).

\section{Product life}

The actual product life of cigarettes is relatively short. The speed at which a consumer will smoke a packet of Dunhill International cigarettes depends not only on the frequency of their smoking habit, but also based on whether they are a 'social smoker' and the size of the cigarette packet that was purchased. Generally, a packet of 25 cigarettes will be smoked within a week of purchase (Action on Smoking and Health, 2006). Cigarette smoke created during this stage is a known dangerous pollutant that affects air quality (Woodward, 2001).

\section{Waste management/end of life}

The last stage of the product life cycle is heavily impacted by how the smoker chooses to dispose of the cigarette butt. The three options are either disposing of the cigarette butt into a normal bin, littering the cigarette butt on to the ground, or disposing of it through a cigarette recycling program. If a cigarette is left in an ashtray it will normally simply be put into ordinary waste disposal systems. Cigarette butts that make their way into normal bins will typically become landfill, where they will eventually break down within $12-15$ years (Wells, 2015). 
Cigarette butts are the most littered item in Australia, and this is true for many other countries as well. More than a third of the 24 billion filtered cigarettes sold every year in Australia are littered, and six out of every ten Australian smokers admit to littering their cigarette butts outdoors (Reid, 2014). Cigarette butts will often find their way into waterways and go into the oceans. Many cigarettes that go into the oceans will be accidentally swallowed by marine life, leading to their death (Slaughter et al., 2011).

Various countries have cigarette recycling programs, but they are not commonly used on a widespread basis. In 2014, Australia became the ninth country to join a cigarette recycling scheme (Smith, 2014). The initiative was achieved through a partnership between TerraCycle and Australia Post, with funding from tobacco industry members including British American Tobacco. Ten-and-a-half million cigarette butts were captured through the recycling scheme in which TerraCycle separated the cigarettes and packaging by composition and melted them into hard plastic that could be remoulded to make new recycled industrial products (TerraCycle, 2015). This is highly notable development as it is a small step towards a 'closed-loop' system and marks a major shift in ecological design as described in Natural Capitalism (Hawken et al., 1999). However, the tobacco industry withdrew funding for the initiative at the end of 2015 without explanation (Clean Up Australia, 2015).

\section{Economic impacts of Dunhill International cigarettes}

\section{Negative economic impacts}

There are a large number of negative economic externalities associated with tobacco products, including Dunhill International cigarettes. Many costs associated with the product are not reflected in the price of cigarettes (Proctor, 2011). For example, the cost does not take into account the economic costs borne by all taxpayers through having to pay for smokers' increased healthcare costs when they have higher and more frequent medical bills. It also doesn't take into account the impact of smokers' early death on the economy, and their larger number of sick days when compared with non-smokers. Nor does it take into account the cost of cleaning up littered cigarette butts, or even incidental costs like the lower resale value of cars used by frequent smokers.

The true costs of cigarettes being much higher than the actual costs means that they should undoubtedly be taxed rather than subsidised. A study found that if cigarette packets reflected their true costs, they would cost US\$40 a packet, even after taking into account the reduced amount of pension money given to smokers who die early 
(Sloan, 2004). Taxing tobacco products including, Dunhill International cigarettes, therefore makes sense, since it not only helps to recuperate money to go towards costs to the healthcare system, but the higher price also has the added benefit of being a disincentive to discourage people from smoking (Tobacco Free Kids, 2016).

\section{'Positive' economic impacts and the broken window fallacy/opportunity cost}

The tobacco sector employs 100 million people worldwide, according to a report undertaken in 2003 by the International Labour Organization, an agency of the United Nations. Of those 100 million people, only about 1.2 million are employed in the manufacturing of tobacco products. Roughly 40 million employees work in tobacco growing and processing, and 20 million more work in related industries in India and Indonesia. The remainder are employed in tobacco-related processes and industries, for example distribution, sales and marketing. There are also many people employed in organisations fighting against tobacco consumption (International Labour Organization, 2003).

The tobacco industry makes a substantial contribution to global economic activity, and many countries rely heavily on the industry to contribute to their economy. Malawi is an excellent example of this, and is also one of the nations from which British American Tobacco sources much of its tobacco. Malawi has 13 per cent of its GDP attributed to the tobacco industry, and tobacco also accounts for 60 per cent of its total exports as well as 23 per cent of Malawi's total tax base (Jaffee, 2003).

It is easy to make the mistake of thinking that these are positive economic impacts of the tobacco industry. Indeed, it is true that large elements of the global economy rely heavily on the existence of the tobacco industry. However, consider 'the broken window fallacy'. The fallacy puts forth a situation in which a window is intentionally broken for the purpose of generating economic activity as a result of the glazier being employed to fix it. It illustrates that there is actually no net benefits to society, as a result of the associated opportunity cost related to the window being fixed (Bastiat, 2011).

It is worthwhile considering this broken window fallacy and the opportunity cost of allocating resources to the tobacco industry in relation to the seemingly positive economic impacts of the existence of the tobacco industry. If the industry never came into existence in the first place, the individuals currently employed in the industry would likely be employed in another more constructive and beneficial area of the economy. The vast amount of land being used to grow harmful tobacco products, the wood pulp in the filter, and the seed flax paper could instead be used in better ways, such as to farm more vital agricultural products, and the factories used to process tobacco could instead be used to process and manufacture products 
with much less harmful impacts. It is therefore improper and illogical to argue that the 'seemingly positive' economic impacts of tobacco products outweigh the overwhelmingly negative economic impacts.

\section{Ecological and environmental impacts of Dunhill International}

There is a large range of negative and environmental impacts associated with all aspects of cigarettes, from the first stage of the life cycle through to the last stage. In the raw material stage, land is often cleared and deforested in order to make room for tobacco plantations. Thirty per cent of the greenhouse gases added to the atmosphere each year are due to deforestation, and in Tanzania alone more than 60,000 hectares of land undergo deforestation annually in order to grow and cure more tobacco (Makoye, 2012). Furthermore, the agro-chemicals and fertilisers used in the tobacco crop production can often cause long-lasting land damage. Water is also used in order to help the plant grow faster, despite it being a very precious resource in many African nations where tobacco is grown (Proctor, 2011). The processing and manufacturing stage of the product also tends to create pollution as a by-product of the machinery used. These negative impacts are all also true for the wood pulp used to create the filter, and the seed flax used to create the paper (Vernier, 1998).

Ecological impacts of cigarettes are also felt while the product is in use and at the end of its product life. Pets that belong to people who frequently smoke are more likely to get cancer themselves as a result of the second-hand smoke since it is a deadly pollutant in the air (Coates, 2014). As well, as previously discussed, the large amount of litter created by cigarettes is another obvious issue. Marine life frequently dies due to swallowing the remnants of cigarettes (Slaughter et al., 2011). Furthermore, poor disposal at the end of the product life cycle is a serious environmental concern due to fire risks. Every year in Australia, more than 4,500 fires are started due to cigarette butts being thrown away (Montgomery, 2010).

\section{Social and ethical concerns relating to Dunhill International}

There are a number of social issues surrounding the smoking of cigarettes including Dunhill International. Passive smoking is an obvious issue affecting those who are around smokers, since they are more likely to develop smoking-related illnesses themselves. The benefits and burdens associated with the product have been previously discussed in the 'Economic impacts' section. 'Big tobacco' is the key party benefiting from the industry through large profits. However, many nations 
that allow tobacco companies to donate to political parties benefit as well. Political donations by the sector are a contentious issue, since they may be used in an effort to keep regulation of the industry at low levels (Williams, 2012).

There are many arguments against regulation and measures to prevent smoking. Some individuals view government intervention in the sector as going against their values of what it means to have a free society. This view was particularly apparent when plain packaging was introduced in Australia, with many decrying the move as a step towards a 'nanny state' (Chung, 2014). Furthermore, many view taxes on cigarettes as an unfair, regressive tax that targets poor people, since lower income individuals generally smoke more and spend a higher percentage of their disposable income on cigarettes compared to wealthier individuals (Regidor et al., 2007).

The tobacco industry, including British American Tobacco, attempts to position itself as caring immensely about the welfare of individuals and attempting to mitigate negative impacts (British American Tobacco, 2016d). Based on what is spruiked by the companies when compared with actual data of the negative impacts of their products, it is likely that cigarette companies simply use their few positive initiatives as ways of attaining good publicity, while actually caring very little about the harm the industry causes. The very short-lived and previously discussed TerraCycle program for the recycling of cigarette butts can be seen as evidence backing this view (Clean Up Australia, 2015).

\section{Conclusion and recommendations}

It is clear that cigarettes such as Dunhill International are immensely harmful not only for the individual, but also for the cigarettes' adverse environmental, economic and social impacts. A global path towards ending tobacco consumption should be investigated, through subsidising products that help individuals quit smoking, and implementing higher taxes on cigarettes to reflect their true economic price. Importantly, there must be more cooperation between nations to ensure that measures are taken on a global scale, perhaps through the United Nations. Political donations from 'Big Tobacco' companies like British American Tobacco should be banned globally to ensure politicians are not pressured to take their biased viewpoint.

It should be noted that a total and sudden ban (as suggested by Proctor, 2011) is not advised, due to the immense economic harm that would be caused to the global economy and the 100 million individuals who are in some way employed by the industry. A slow transition over a number of years is more appropriate. Caps on cigarette production are perhaps a better alternative to consider as a way of influencing the supply side of the economic equation. If these caps were progressively lowered, it would allow for the agricultural and manufacturing sectors to slowly adjust to the change. 
It should be stressed that these are all simply ideas for a path towards lowering all negative impacts over the long term and they would require extensive further investigation before any policy decision is considered.

\section{Bibliography}

Action on Smoking and Health. (2006). Smoking Statistics: Who Smokes and How Much, London, UK. Retrieved from ash.org.uk/information/facts-and-stats/ fact-sheets (accessed 5 April 2016).

Bastiat, F. (2011 [1850]). 'That Which is Seen, and That Which is Not Seen'. In The Bastiat Collection, 2nd edition. Alabama: Ludwig von Mises Institute. Retrieved from mises.org/sites/default/files/The\%20Bastiat\%20Collection_4.pdf.

British American Tobacco. (2016a). About Tobacco. Retrieved from www.bat.com/group/sites/uk__9d9kcy.nsf/vwPagesWebLive/DO52ADR2 (accessed 6 April 2016).

British American Tobacco. (2016b). Key Group Statistics. Retrieved from www.bat. com/group/sites/UK_ 9D9KCY.nsf/vwPagesWebLive/DO6LMNZV (accessed 5 April 2016).

British American Tobacco. (2016c). Manufacturing. Retrieved from www.bat.com/ production (accessed 4 April 2016).

British American Tobacco. (2016d). Who We Are. Retrieved from www.bata.com.au/ group/sites/uk_9d9kcy.nsf/vwPagesWebLive/DO52ADCY (accessed 4 April 2016).

Chung, F. (2014). 'Has the Nanny State Gone too Far?' News.com.au. Retrieved from www.news.com.au/finance/economy/plain-packaging-bicycle-helmetlaws-nightclub-lockouts-has-the-nanny-state-gone-too-far/news-story/ cf30157b7e7547e796b0460fbfdaecaa (accessed 10 April 2016).

Clean Up Australia. (2015). Clean Up: Recycling Cigarette Butts. Retrieved from www.cleanup.org.au/au/Whatelsewesupport/recycling-cigarette-butts.html (accessed 6 April 2016).

Coates, J. (2014). Second Hand Smoke and Cancer Risk for Pets. Retrieved from www. petmd.com/blogs/thedailyvet/dr-coates/2014/june/risks-second-hand-smokedogs-and-cats-31821 (accessed 5 April 2016).

Hawken, P., Lovins, A. \& Lovins, L. (1999). Natural Capitalism. Boston: Little, Brown \& Co. 
International Labour Organization. (2003). Up in Smoke: What Future for Tobacco Jobs? Retrieved from www.ilo.org/global/about-the-ilo/newsroom/features/ WCMS_071230/lang--en/index.htm (accessed 17 April 2016).

Jaffee, S. (2003). Malawis Tobacco Sector: Standing on One Strong Leg is Better than on None. Africa Region Working Paper Series no. 55, World Bank.

Ken-cheng, L. (2008). 'There is Not Enough Land to Off-set Emissions', Taipei Times. Retrieved from www.taipeitimes.com/News/editorials/ archives/2008/04/11/2003408944 (accessed 12 April 2016).

Makoye, K. (2012). 'TobaccoFarms DriveMajor Deforestation in Tanzania'. Thomson Reuters Foundation. Retrieved from news.trust.org//item/201212262207004cney/ (accessed 6 April 2016).

Mayer, I. (2010). 'Dunhill Cigarettes-the Best Brand of British Cigarettes'. Retrieved from www.tobaccoreviews.net/dunhill-cigarettes-the-best-brand-ofbritish-cigarettes (accessed 5 April 2016).

Montgomery, G. (2010). 'Ban on High Fire Risk Cigarettes Comes into Effect'. Fire \& Rescue NSW. Retrieved from www.fire.nsw.gov.au/news.php?news=1583 (accessed 4 April 2016).

Proctor, R. (2011). Golden Holocaust: Origins of the Cigarette Catastrophe and the Case for Abolition. Berkeley: University of California Press.

Regidor, E., Pascual, C. \& Gutiérrez-Fisac, J. (2007). 'Increasing the Price of Tobacco: Economically Regressive Today and Probably Ineffective Tomorrow'. European Journal of Cancer Prevention, 16(4), 380-384. doi.org/10.1097/01. cej.0000228403.60729.76

Reid, C. (2014). Smokers Crowned Australia's Worst Litterbugs. Keep Australia Beautiful. Retrieved from kab.org.au/smokers-crowned-australias-worstlitterbugs (accessed 3 April 2016).

Slaughter, E., Gersberg, R., Watanabe, K., Rudolph, J., Stransky, C. \& Novotny, T. (2011). 'Toxicity of Cigarette Butts, and their Chemical Components, to Marine and Freshwater Fish'. Tobacco Control, 20(Supplement 1), i25-i29. doi.org/10.1136/tc.2010.040170

Sloan, F. (2004). The Price of Smoking. Cambridge, Mass.: MIT Press.

Smith, B. (2014). 'Australia gets Cigarette Butt Recycle Scheme with TerraCycle', The Sydney Morning Herald. Retrieved from www.smh.com.au/national/ australia-gets-cigarette-butt-recycle-scheme-with-terracycle-20140303-340jt. html (accessed 2 April 2016). 
Stanton, H. (2005). 'The Millennium Development Goals and Tobacco Control: An Opportunity for Global Partnership'. Tobacco Control, 14(6), 429-432. doi. org/10.1136/tc.2005.014423

TerraCycle. (2015). Cigarette Waste Recycling Program. Retrieved from www. terracycle.com/en-US/brigades/cigarette-waste-brigade (accessed 3 April 2016).

Tobacco Free Kids. (2016). Raising Cigarette Taxes Decreases Smoking. Retrieved from www.tobaccofreekids.org/research/factsheets/pdf/0146.pdf (accessed 5 April 2016).

Vernier, G. (1998). The U.S. Tobacco Industry. US Department of Agriculture Economics Research Service.

Wells, S. (2015). 'Cigarette Filters take Fifteen Years to Disintegrate'. Natural News. Retrieved from www.naturalnews.com/048988_cigarette_filters_smoking cessation_lung_damage.html (accessed 3 April 2016).

Wilberg, L. \& Vermeulen, C. (2008). Ottawa Pipe Club. Retrieved from web.archive. org/web/20160617123201/http://ottawapipeclub.ca/odyssey.htm (accessed 3 April 2016, site discontinued).

Williams, A.S. (2009). Life Cycle Analysis: A Step by Step Approach. Champaign, IL: Illinois Sustainable Technology Centre.

Williams, R. (2012). 'Regulating Political Donations by Companies: Challenges and Misconceptions'. Modern Law Review, 75(6), 951-980. doi.org/10.1111/j.14682230.2012.00932.x

Woodward, A. (2001). 'How Many Deaths are Caused by Second Hand Cigarette Smoke?' Tobacco Control, 10(4), 383-388. doi.org/10.1136/tc.10.4.383 
This text is taken from The ANU Undergraduate Research Journal, Volume Eight, 2016, edited by Daniel McKay, published 2017 by ANU eView, The Australian National University, Canberra, Australia.

dx.doi.org/10.22459/AURJ.08.2016.13 